\title{
Differential Effects of Nerve Transection on the ACh and GABA Receptors of Chick Ciliary Ganglion Neurons
}

\author{
Adrienne E. McEachern, ${ }^{a}$ Michele H. Jacob, ${ }^{b}$ and Darwin K. Berg \\ Department of Biology, University of California, San Diego, La Jolla, California 92093
}

Chick ciliary ganglion neurons have nicotinic acetylcholine receptors (AChRs) that mediate chemical transmission through the ganglion, and $\mathrm{GABA}_{\mathrm{A}}$ receptors of unknown significance. Previous experiments examining the role of cellcell interactions in regulating neuronal AChRs have shown that postganglionic axotomy of ciliary ganglia in newly hatched chicks causes a 10-fold decline in total AChRs within $5 \mathrm{~d}$ compared with unoperated contralateral ganglia and that preganglionic denervation causes a 3-fold decline within $10 \mathrm{~d}$. Many of the AChRs are known to be intracellular; of those present on the cell surface, only a small fraction appears to be functionally available normally. In the present experiments, the effects of the operations on functional $A C h R s$ and $\mathrm{GABA}_{\mathrm{A}}$ receptors in the plasma membrane of the neurons were examined by removing the ganglia 5 d after axotomy or $10 \mathrm{~d}$ after denervation, dissociating them into single cells, and immediately measuring their $\mathrm{ACh}$ and GABA sensitivities with intracellular recording techniques. The ACh sensitivity of axotomized ciliary ganglion neurons was reduced 10-fold compared with neurons from unoperated contralateral ganglia of the same chicks. The reduction could be largely accounted for by a decrease in the maximum response and did not arise from a change either in the doseresponse curve or the acetylcholinesterase activity of the neurons. Autoradiographic studies using a radiolabeled antiAChR monoclonal antibody also demonstrated a substantial decrease in the total number of surface AChRs associated with axotomized neurons. In contrast, axotomy had no unilateral effect on the GABA response. Denervation had little if any effect on the ACh response of the neurons, and autoradiography confirmed that no detectable change occurred in the number of surface AChRs. Denervation did reduce GABA responses unilaterally about 2-fold. The results demonstrate that $\mathrm{AChRs}$ and $\mathrm{GABA}_{\mathrm{A}}$ receptors on the neurons are regulated differently by cell-cell interactions in vivo. Moreover, the preganglionic input and the synaptic target (end organ) of the ganglion appear to contribute different

Received Nov. 25, 1988; revised May 4, 1989; accepted June 6, 1989.

We thank James Johnson for expert technical assistance with the operations. Grant support was provided by NIH grants NS12601 and NS21725 (M.H.J.), the Pfeiffer Foundation (M.H.J.), the Muscular Dystrophy Association, and the American Heart Association with funds contributed in part by the California Heart Association.

Correspondence should be addressed to Darwin K. Berg, Department of Biology, B-022, University of California, San Diego, La Jolla, CA 92093.

a Present address: Department of Neurobiology, Stanford University School of Medicine, Stanford, CA 94305.

Present address: Worcester Foundation for Experimental Biology, Shrewsbury, MA 01545.

Copyright $C 1989$ Society for Neuroscience $0270-6474 / 89 / 113899-09 \$ 02.00 / 0$ regulatory signals. Last, the results show that neurons can independently regulate surface and internal pools of receptors in response to the signals, at least in the case of AChRs.

Cell-cell interactions regulate synaptic components at the neuromuscular junction in a manner that contributes to the formation and stabilization of the functioning synapse. Primary among these is the role of innervation in controlling the number, type, and distribution of nicotinic acetylcholine receptors (AChRs) in muscle (for reviews, see Fambrough, 1979, and Schuetze and Role, 1987).

Principles guiding regulation of synaptic components on neurons are less clear. Strong precedent exists for transsynaptic regulation of certain neuronal functions. For example, synaptic input from preganglionic terminals increases the level of tyrosine hydroxylase in rat sympathetic ganglion neurons (Mueller et al., 1969; Black et al., 1985). Preganglionic innervation also helps maintain choline acetyltransferase and acetylcholinesterase levels in pigeon ciliary ganglion neurons (Giacobini et al., 1979). Retrograde transport of nerve growth factor from the periphery supports the growth and development of sympathetic neurons, and stabilizes synaptic contacts on them $(\mathrm{Nja}$ and Purves, 1978). The regulation of neuronal AChRs by cell-cell interactions, however, has been the subject of several studies that have produced divergent results.

Parasympathetic cardiac ganglion neurons in frog and mudpuppy have a nonuniform distribution of ACh sensitivity, consistent with a synaptic localization of the receptors. Denervation of the neurons causes the appearance of a more uniform distribution of sensitivity, an increase in the mean ACh sensitivity of the neurons, and a decrease in the mean rise time of the response to iontophoretically applied $\mathrm{ACh}$ at random sites on the soma (Kuffler et al., 1971; Roper, 1976; Dennis and Sargent, 1979). The data suggest that removing the presynaptic innervation results in the accumulation of extrasynaptic AChRs on the neurons as occurs on denervated skeletal muscle fibers. Frog sympathetic neurons also have a nonuniform distribution of ACh sensitivity, but in this case denervation produces no change in the magnitude, distribution, or time course of the $\mathrm{ACh}$ responsc (Dunn and Marshall, 1985). The basis for these different observations remains unresolved.

An anti-AChR monoclonal antibody has been used to quantitate changes in the number of neuronal AChRs following denervation. Ten days after preganglionic denervation of ciliary ganglia in newly hatched chicks the total number of ganglionic AChRs declines to $35 \%$ of those present in unoperated contralateral ganglia of the same chicks (Jacob and Berg, 1987). Measuring the amount of $\alpha 3$ mRNA encoding a neuronal AChR 
subunit in the ganglia indicates a similar decline (Boyd et al., 1988). These results are unexpected in view of the increased or maintained ACh sensitivities observed for other systems after denervation.

The quantitation of AChRs with anti-AChR antibodies was carried out on detergent extracts that included surface receptors as well as receptors inside the cells. About two-thirds of the total AChRs associated with the neurons are likely to be intracellular (Jacob et al., 1986; Stollberg and Berg, 1987). Accordingly, a large decrease in the size of the intracellular pool in response to denervation could have obscured an increase or an absence of change in the number of surface AChRs on the cells. This possibility was examined with immunohistochemistry at the electron microscope level using an anti-AChR monoclonal antibody together with an HRP-conjugated secondary antibody. Though only semiquantitative, the results indicated that preganglionic denervation substantially reduces the intracellular pool of AChRs while having little effect on the number of synaptic AChRs (Jacob and Berg, 1988).

A second type of cell-cell interaction thought to regulate neuronal AChRs involves the target tissue innervated by the neurons. Postganglionic axotomy of the ciliary neuron subpopulation in ciliary ganglia of newly hatched chicks has been shown to produce an 8-fold decline in the ACh response in 3-4 d (Brenner and Martin, 1976). In agreement with the physiological results, the total number of AChRs in ganglia assayed with an anti-AChR monoclonal antibody declines to a tenth of those present in unoperated contralateral ganglia within $5 \mathrm{~d}$ (Jacob and Berg, 1987). The amount of $\alpha 3$ mRNA declines to a quarter (Boyd et al., 1988). Immunohistochemical studies suggest that both the surface and intraccllular pool of AChRs are reduced by axotomy (Jacob and Berg, 1988).

The present studies examine the effects of preganglionic denervation and postganglionic axotomy on functional AChRs and $\mathrm{GABA}_{\mathrm{A}}$ receptors on chick ciliary ganglion neurons. This was motivated in part by the finding that the efficacy of neuronal AChRs in the plasma membrane can be altered by regulatory events (Marshall, 1985; Margiotta et al., 1987a, b; for bovine adrenal chromaffin AChRs, however, see note added in proof). Most AChRs on chick ciliary ganglion neurons appear to exist in a "silent" mode; some can be converted to a functionally available state by a cAMP-dependent process (Margiotta et al., $1987 \mathrm{a}, \mathrm{b})$. Consequently, changes in the number of functional AChRs can occur quite independently from changes in the number of surface AChRs. In addition to the electrophysiological measurements, a radiolabeled anti-AChR monoclonal antibody was used in the present experiments to examine the relative number of surface AChRs under the test conditions, as a complement to previous histochemical comparisons of $\mathrm{AChR}$ levels on the neurons.

$\mathrm{GABA}_{\mathrm{A}}$ receptors on the neurons have the ability to inhibit transmission through the ganglion (McEachern et al., 1985; McEachern and Berg, 1988). Their physiological significance remains unknown since no endogenous source of agonist has been identified for the receptors in the ganglion. Regulation of $\mathrm{GABA}_{\mathrm{A}}$ receptors by cell-cell interactions has been explored in the rat substantia nigra where denervation has been reported to increase both the GABA sensitivity of nigral neurons (Waszczak et al., 1981) and the total number of $\mathrm{GABA}_{\mathrm{A}}$ receptors there (Waddington and Cross, 1978; Guidotti et al., 1979; Pan et al., 1983; but see Corda et al., 1986). Measurements of GABA sensitivity were included in the present study both to evaluate the role of cell-cell interactions in regulating $\mathrm{GABA}_{\mathrm{A}}$ receptors and to compare the regulation with that of AChRs on the neurons. No probes of sufficient sensitivity were available to estimate the total number of surface $\mathrm{GABA}_{\mathrm{A}}$ receptors as was done for AChRs.

The results indicate that preganglionic denervation for $10 \mathrm{~d}$ affects neither the magnitude of the $\mathrm{ACh}$ response nor the number of surface AChRs detected with the anti-AChR monoclonal antibody. Denervation does, however, reduce the size of the GABA response by a factor of 2 . Complete postganglionic axotomy has a very different effect. Within $5 \mathrm{~d}$ it reduces the $\mathrm{ACh}$ response by a factor of 10 and substantially reduces the number of surface AChRs detected by the antibody while having no unilateral effect on the size of the GABA response of the cells. The results suggest that cell-cell interactions influence both the AChRs and the $\mathrm{GABA}_{\mathrm{A}}$ receptors on the neurons and that different regulatory mechanisms are involved for the 2 types of receptors. A preliminary account of some of these results has appeared (McEachern et al., 1988).

\section{Materials and Methods}

Operations. Surgical preganglionic denervation or postganglionic axotomy was performed on ciliary ganglia in chicks 2-3 d after hatching as previously described (Jacob and Berg, 1987, 1988). Axotomy or denervation was performed on a single ciliary ganglion per chick, reserving the contralateral ganglion as a control. After the operations and recovery from anesthesia, chicks were maintained in a heated brooder for $5 \mathrm{~d}$ following axotomy and $10 \mathrm{~d}$ following denervation. The total absence of a pupillary light reflex was used as a criterion for a successful operation. The ganglion was also examined during dissection to confirm that the appropriate nerves had been completely severed. The success rate of the surgery was $90 \%$.

Ganglion dissociation. At the indicated times, ganglia were dissected into a Ca ${ }^{2+}$-free salt solution containing (in $\mathrm{mm}$ ) $145.0 \mathrm{NaCl}, 5.3 \mathrm{KCl}$, $3.0 \mathrm{MgCl}_{2}, 5.6$ glucose, and 5 HEPES (pH 7.4) (modified from Dichter and Fischbach, 1977). After trimming away residual processes, the ganglia were cut into quadrants and incubated at $37^{\circ} \mathrm{C}$ for $40-50 \mathrm{~min}$ in the $\mathrm{Ca}^{2+}$-free salt solution with $4 \mathrm{mg} / \mathrm{ml}$ collagenase and $0.5 \mathrm{mg} / \mathrm{ml}$ deoxyribonuclease I. Afterwards, the ganglia were washed 4 times and resuspended at $37^{\circ} \mathrm{C}$ in recording solution consisting of (in $\mathrm{mm}$ ) 137 $\mathrm{NaCl}, 5.4 \mathrm{KCl}, 0.81 \mathrm{MgSO}_{4}, 0.92 \mathrm{Na}_{2} \mathrm{HPO}_{4}, 0.44 \mathrm{KH}_{2} \mathrm{PO}_{4}, 5.4 \mathrm{CaCl}_{2}$, 5.6 glucose, 2.5 HEPES (pH 7.4), and the essential amino acids and vitamins present in Eagle's minimal essential medium. The suspension was then triturated and plated onto $35 \mathrm{~mm}$ dishes previously coated with poly-D-lysine. The dishes had been coated by incubating them for $5 \mathrm{hr}$ at $4^{\circ} \mathrm{C}$ in $0.13 \mathrm{M}$ sodium borate, $\mathrm{pH} 8.6$, containing $1 \mathrm{mg} / \mathrm{ml}$ poly$\mathrm{D}$-lysine and then rinsing them for $20 \mathrm{~min}$ with distilled water followed by air drying. Cells were allowed to settle and attach undisturbed to the substratum for $15 \mathrm{~min}$ at $37^{\circ} \mathrm{C}$ prior to electrophysiological testing. Dissociated cell yields were low (ca. $30-40$ viable neurons per ganglion) because of the difficulty in disrupting posthatch ganglia without damaging the cells. Cells selected for testing were judged to be healthy by morphological and electrical criteria (see Results). Operated ganglia were usually dissociated and tested first while control ganglia were kept on ice prior to trimming away processes. The ice storage did not alter control values since they were indistinguishable from values obtained for neurons dissociated from freshly dissected control ganglia.

Electrophysiology. Intracellular recordings were obtained from freshly dissociated ciliary ganglion neurons using techniques previously described (O'Lague et al., 1978; McEachern et al., 1985; McEachern and Berg, 1988). Dishes were maintained at $37^{\circ} \mathrm{C}$ on the stage of an inverted microscope and continuously perfused with recording solution while isolated cells, relatively free of attached debris, were selected for testing. $\mathrm{ACh}$ and GABA sensitivities were determined by measuring changes in membrane conductance caused by agonist being pressure ejected (1$3 \mathrm{psi}$ for 1-3 sec) from single (4-6 $\mu \mathrm{m}$ tip diameter) or multibarrel (7$8 \mu \mathrm{m}$ tip diameters) pipettes positioned $10-20 \mu \mathrm{m}$ from the soma (Choi and Fischbach, 1981; McEachern et al., 1985; McEachern and Berg, 1988). Sensitivities determined in this way are probably the summed response of receptors on the soma since the procedure immerses the soma in the test compound. Sensitivities were calculated as the differ- 
Table 1. Properties of dissociated neurons

\begin{tabular}{llll} 
Ganglia & $\begin{array}{l}\text { Resting potential } \\
(\mathrm{mV})\end{array}$ & $\begin{array}{l}\text { Input resistance } \\
(\mathrm{M} \Omega)\end{array}$ & $\begin{array}{l}\text { Diameter } \\
(\mu \mathrm{m})\end{array}$ \\
\hline Normal, axotomy age-matched & $-57.5 \pm 1.0(44)$ & $163 \pm 12(44)$ & $22.4 \pm 0.6(44)$ \\
Contralateral to axotomized & $-55.2 \pm 1.2(25)$ & $157 \pm 13(25)$ & $25.2 \pm 1.0(24)$ \\
Axotomized & $-55.7 \pm 1.1(35)$ & $143 \pm 16(35)$ & $25.4 \pm 0.8(34)$ \\
Normal, denervation age-matched & $-58.1 \pm 0.8(50)$ & $154 \pm 8(48)$ & $23.4 \pm 0.6(50)$ \\
Contralateral to denervated & $-55.1 \pm 1.5(15)$ & $190 \pm 22(16)$ & $23.8 \pm 1.0(16)$ \\
Denervated & $-59.3 \pm 1.3(40)$ & $194 \pm 16(39)$ & $21.0 \pm 0.6(39)$ \\
\hline
\end{tabular}

ence between the maximum conductance measured in the presence of agonist and the resting conductance prior to application of agonist. Unless otherwise indicated, the results have been corrected for differences in cell size by expressing them as conductance per soma surface area $\left(\mathrm{pS} / \mu \mathrm{m}^{2}\right)$ for individual neurons, where the surface area was calculated from the cell diameter measured in the microscope. Data were accepted only when the neuron had a resting potential more negative than $-45 \mathrm{mV}$ and could firc ovcrshooting action potentials in response to intracellular stimulation, and when the recording electrode was no more than $3 \mathrm{mV}$ out of balance when withdrawn from the neuron. ACh was usually applied at $30 \mu \mathrm{M}$ to obtain accurately quantifiable responses with little desensitization. The $\mathrm{EC}_{50}$ for $\mathrm{ACh}$ is about $100 \mu \mathrm{M}$ (Smith et al., 1983). Since GABA responses were usually small, the compound was routinely tested at $50 \mu \mathrm{M}$, a concentration near the $\mathrm{EC}_{50}$ for $\mathrm{GABA}$ (McEachern and Berg, 1988). Voltage-current relationships for unoperated neurons were linear over the range of -60 to $-35 \mathrm{mV}$. In some cases, ACh depolarized the membrane beyond $-35 \mathrm{mV}$, but no corrections were made for contributions from voltage-dependent ionic conductances because of the difficulty in accurately assessing the resting slope conductance at these voltages. Correcting the data would have had little effect on the denervation results since the operated and control neurons had comparable sensitivities. A correction might have exaggerated the difference in the axotomy studies since only the control neurons would have had sufficient sensitivity to fall into this range. In any case, the corrections would have been small (Margiotta and Berg, 1986).

Sensitivity data were routinely compared by constructing log-normal distributions and calculating the geometric means in each case. This was done because the distribution of response magnitudes was skewed in each case rather than normal (Dennis and Sargent, 1979; Hancock et al., 1988). Unless otherwise indicated, the data are presented as the antilog of the geometric mean with an SEM calculated as the average of the differences between the antilog of the upper and lower geometric error limits. The geometric means were compared statistically using a 2-tailed Student's $t$ test.

In some cases, intracellular recordings were made from neurons in intact ciliary ganglia freshly dissected from newly hatched chicks to determine the neuronal response to bath perfusion with $100 \mu \mathrm{M}$ GABA. The procedures used were identical to those previously described for embryonic ganglia (McEachern et al., 1985).

To test the effects of a cholinesterase blocker on ACh sensitivities, neurons were freshly dissociated from ganglia of 12-17 d posthatch chicks and were tested for responses to ACh and carbachol to establish control values. Neostigmine $(3 \mu \mathrm{M})$ was then applied to the dish for $10-$ $60 \mathrm{~min}$ and cells tested to determine whether ACh responses had been altered as reflected either in the absolute mean value of ACh sensitivity or in the ratio of responses to ACh and carbachol.

Autoradiography. Autoradiography was carried out on dissociated ciliary ganglion neurons attached to poly-D-lysine dishes using the radioiodinated anti-AChR monoclonal antibody ${ }^{125}$ I-mAb 35 (Smith et al., 1986; Halvorsen and Berg, 1987). The dishes were rinsed once at room temperature with a salt solution similar to that used to dissociate the neurons $\left(\mathrm{Ca}^{2+}-\mathrm{free}\right)$ except that it was modified to contain $5.4 \mathrm{~mm}$ $\mathrm{CaCl}_{2}, 1.8 \mathrm{mM} \mathrm{MgCl}_{2}$, and $10 \%$ heat-inactivated horse serum. The cultures were then incubated for $1 \mathrm{hr}$ at room temperature in $1 \mathrm{ml}$ of the solution containing $5 \mathrm{nM}{ }^{122} \mathrm{I}-\mathrm{mAb} 35$. [The $K_{D}$ for ${ }^{125} \mathrm{I}-\mathrm{mAb} 35$ binding is about $1 \mathrm{nM}$ (Smith et al., 1985).] The cultures were rinsed 4 times, fixed in $2 \%$ glutaraldehyde plus $2 \%$ paraformaldehyde for $1 \mathrm{hr}$ at room temperature, rinsed again, air-dried, and processed for autoradiography as previously described (Smith et al., 1983). ${ }^{125}$ I-mAb 35 specific activ- ities varied from 0.5 to $2.8 \times 10^{18} \mathrm{cpm} / \mathrm{mol}$, and corresponding exposure times varied from 12 weeks to $8 \mathrm{~d}$. Nonspecific binding was determined by including $250 \mathrm{nM}$ unlabeled mAb 35 in the incubation with ${ }^{125} \mathrm{I}-\mathrm{mAb}$ 35 .

To compare labeling among experiments, neurons were divided into 4 categories based on the relative number of grains associated with the cells. The criteria for the categories were established individually for each experiment by examining the range of labeling obtained in that case; unoperated contralateral neurons were included in each experiment. The categories included (1) unlabeled, (2) lightly labeled, (3) moderately labeled, and (4) heavily labeled neurons. The number of cells in each category was then expressed as a percent of the total cells counted so that the results from several experiments could be averaged. This approach was necessary since the absolute number of grains per neuron varied among experiments, depending on the time of exposure and specific activity of the antibody.

Materials. Embryonated eggs from White Leghorn chickens were obtained locally from McIntyre Poultry (Lakeside, CA) and maintained and hatched at $39^{\circ} \mathrm{C}$ in a humidified incubator. Occasionally newly hatched chicks were purchased from Spafas (Norwich, CT). mAb 35 was purified and radioiodinated by the chloramine $\mathrm{T}$ method to specific activities of $0.6-2 \times 10^{18} \mathrm{cpm} / \mathrm{mol}$ as previously described (Smith et al., 1985). GABA, ACh chloride, $\delta$-tubocurarine, carbamylcholine chloride (carbachol), neostigmine bromide, picrotoxin, deoxyribonuclease I, and sodium pentobarbital were purchased from Sigma Chemical Co. (St. Louis, MO). Culture media components were obtained from GIBCO (Grand Island, NY), collagenase from Boehringer Mannheim (Indianapolis, IN), methoxyflurane from Pitman-Moore, Inc. (Washington Crossing, NJ), and NTB-2 emulsion from Kodak (Rochester, NY).

\section{Results}

\section{Responses from dissociated neurons}

Only dissociated neurons free of major debris were used for determinations of $\mathrm{ACh}$ and GABA sensitivities. Such cells were selected because they offered the greatest access to applied agonist, thereby increasing the likelihood that the elicited response involved the majority of receptors on the soma. This approach was attractive for quantitative comparisons of agonist responses among cell populations because it minimized the impact of differences both in agonist access and in nonuniform distribution of receptors on the cell soma. Ganglia from newly hatched chicks, however, are relatively resistant to dissociation, presumably because of the connective tissue surrounding the neurons. Accordingly, the yields of viable cells were usually low. This prompted the concern that either the tested neurons might be unrepresentative of the population as a wholc or they might bc damaged in a manner that compromised the measurements.

Several criteria provided reassurance that tested cells were not significantly damaged. Tested neurons, freshly dissociated both from operated and control ganglia, had the phase-bright appearance and general soma morphology expected for ciliary ganglion neurons chronically maintained in culture (Nishi and Berg, 1979). All neurons lested had overshooting action potentials. Little difference was observed in the mean resting potential 


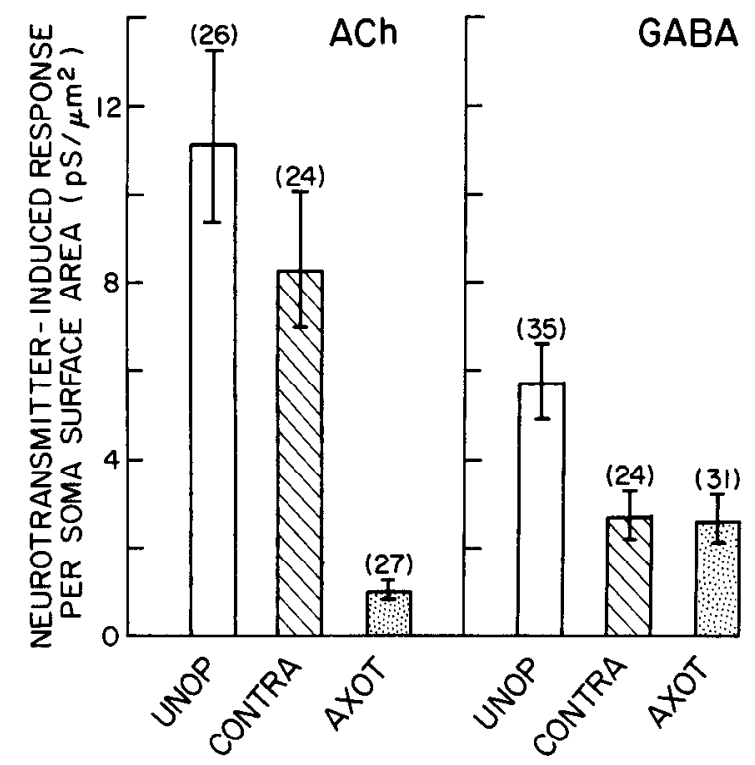

Figure 1. ACh and GABA responses of axotomized neurons. Ciliary ganglia in newly hatched chicks were axotomized by unilaterally transecting the postganglionic nerves, and $5 \mathrm{~d}$ later were removed and dissociated. Isolated neurons largely free of attached debris were tested for responses to $30 \mu \mathrm{M}$ ACh or $50 \mu \mathrm{M}$ GABA pressure applied from nearby pipettes. Unop, normal neurons from unoperated chicks of the same age as operated chicks; contra, unoperated contralateral neurons from operated chicks; axot, axotomized neurons. Each determination represents the antilog geometric mean change in membrane conductance caused by the agonist per soma surface area, and the error bars represent the SEM calculated as described in Materials and Methods. The numbers in parentheses indicate the number of neurons sampled. Data are from 4-6 separate experiments in which 6-7 ciliary ganglia were pooled per dissociation. The mean ACh response of axotomized neurons was significantly lower $(p<0.005)$ than that of either set of control neurons. The mean GABA response of axotomized neurons was not significantly different from those of neurons from unoperated contralateral ganglia of the same chicks, but was lower than that of neurons from normal ganglia of unoperated chicks $(p<0.005)$. The whole-cell mean ACh responses uncorrected for cell size were $1.9 \pm 0.4 \mathrm{nS}(n=28)$ for axotomized neurons and $17.3+2.2 \mathrm{nS}(n=51)$ for axotomized-paired controls (normal and unoperated contralateral neurons combined). Uncorrected whole-cell mean GABA responses were $5.2 \pm 1.2 \mathrm{nS}(n=32)$ for axotomized neurons and $7.1 \pm 1.0(n=60)$ for axotomized-paired controls.

or input resistance of neurons tested from operated, unoperated contralateral, or control ganglia (Table 1). The mean soma diameter was also similar in all cases, though denervated neurons tended to be slightly smaller on average than paired controls (Table 1). The electrophysiological parameters were similar to those previously reported for neurons in intact ciliary ganglia (Brenner and Johnson, 1976), except for 2- to 3-fold higher input resistances. The increased input resistance of isolated neurons has previously been ascribed to loss of the axon hillock during dissociation (Brenner and Martin, 1976).

The dissociation procedure did not appear to diminish significantly neuronal responses to applied agonist. ACh at $30 \mu \mathrm{M}$ induced a mean membrane conductance change of $16.9 \pm 1.6$ $\mathrm{nS}(n=70)$ in neurons freshly dissociated from ganglia of unoperated chicks 1-2 weeks posthatch. This is greater than the mean response of ciliary ganglion neurons from $8 \mathrm{~d}$ embryos after a week of recovery and growth in cell culture (Smith et al., 1983). $\delta$-Tubocurarine applied at $100 \mu \mathrm{M}$ for $20 \mathrm{sec}$ reversibly blocked the subsequent response to $30 \mu \mathrm{M}$ ACh by $96 \pm 1 \%$ ( $n$
$=7$ ), as it does the $\mathrm{ACh}$ response of neurons maintained in culture (Ravdin and Berg, 1979). GABA at $50 \mu \mathrm{M}$ induced a mean response of $7.8 \pm 0.9 \mathrm{nS}(n=65)$ in neurons from unoperated ganglia, and at 200-500 $\mu \mathrm{M}$ elicited a mean response of $26 \pm 3 \mathrm{nS}(n=35)$. For comparison, ciliary ganglion neurons from $8 \mathrm{~d}$ embryos after 4-6 d in culture have a mean response of $11.9 \pm 2.4 \mathrm{nS}(n=46)$ to $50 \mu \mathrm{M}$ GABA (recalculated as geometric mean \pm SE from McEachern et al., 1985). In 2 experiments recording from neurons in intact ganglia from posthatch chicks, bath application of $100 \mu \mathrm{M}$ GABA elicited responses of 33 and $45 \mathrm{nS}$. Picrotoxin applied to freshly dissociated neurons for $20 \mathrm{sec}$ at $100 \mu \mathrm{M}$ reduced the subsequent response to $50 \mu \mathrm{M}$ GABA by $97 \pm 1 \%(n=4)$; after $3-5 \mathrm{~min}$ of washing, the GABA response recovered to $42 \pm 6 \%(n=4)$. Again, similar results have been obtained with ciliary ganglion neurons maintained in cell culture (McEachern et al., 1985).

Another concern derives from the fact that ciliary ganglia are composed of 2 classes of neurons, choroid neurons and ciliary neurons. This presents the possibility that tested neurons were drawn exclusively from one class. In vivo both ciliary and choroid neurons vary considerably in size, but ciliary neurons are generally larger. At $1 \mathrm{~d}$ posthatch they have a mean diameter of $31 \mu \mathrm{m}$, while choroid neurons have a mean diameter of 19 $\mu \mathrm{m}$ (Pilar and Tuttle, 1982). A wide range of soma diameters was observed for neurons freshly dissociated from posthatch ganglia, suggesting that both cell types may have survived the procedure. About $29 \%$ of the tested neurons had diameters $\geq 26$ $\mu \mathrm{m}$, while $35 \%$ had diameters $\leq 22 \mu \mathrm{m}$. In some experiments, mean ACh and GABA sensitivities were calculated not only for the total cell population tested but also for the large $(\geq 26 \mu \mathrm{m})$ and small $(\leq 22 \mu \mathrm{m})$ populations scparatcly. Similar conclusions were found to hold for all populations examined (see below).

\section{Axotomized neurons}

$A C h$ sensitivity. Axotomy produces a dramatic decrease in the ACh sensitivity of ciliary ganglion neurons. Five days after ganglia were axotomized in newly hatched chicks, $30 \mu \mathrm{M} \mathrm{ACh}$ produced responses in the operated neurons that were about 10 -fold lower than those observed for unoperated contralateral neurons from the same chicks and for normal neurons from unoperated chicks (Fig. 1).

The decrease results from a reduction in the maximum $\mathrm{ACh}$ response rather than a shift in the concentration dependence of the response. This was demonstrated first by observing that 0.5 and $1 \mathrm{mM}$ ACh produced equivalent responses from axotomized neurons, indicating that the agonist concentrations were adequate to induce maximal responses as is true with control neurons. Pooling the data for the 2 concentrations yields values for the mean response as being $1.9 \pm 0.5 \mathrm{pS} / \mu \mathrm{m}^{2}(n=12)$ for axotomized neurons and $10.9 \pm 2.4 \mathrm{pS} / \mu \mathrm{m}^{2}(n=15)$ for control neurons, for a 6 -fold difference under these conditions. Desensitization is likely to have a larger effect at these high agonist concentrations. This, together with the small pool size, makes the calculated difference of 6 -fold less reliable than the 10 -fold obtained with $30 \mu \mathrm{M} \mathrm{ACh}$. Changes in cholinesterase levels cannot account for the reduced $\mathrm{ACh}$ response observed with axotomized neurons because similar results were obtained with carbachol, an agonist that is resistant to hydrolysis by such enzymes. Carbachol at $200 \mu \mathrm{M}$ produced mean responses of 0.3 $\pm 0.1 \mathrm{pS} / \mu \mathrm{m}^{2}(n=3)$ from axotomized neurons and $3.8 \pm 0.4$ $\mathrm{pS} / \mu \mathrm{m}^{2}(n=11)$ from control neurons, for a difference of about 13-fold. Moreover, incubating freshly dissociated neurons with 
$3 \mu \mathrm{M}$ neostigmine to block cholinesterase activity had no effect either on the mean ACh sensitivity or on the ratio of $\mathrm{ACh}$ and carbachol responses (data not shown).

Axotomy appears to have reduced the ACh responses both of large and small neurons. At $30 \mu \mathrm{M}$ ACh produced a mean response of $1.1 \pm 0.3 \mathrm{pS} / \mu \mathrm{m}^{2}(n=10)$ in cells with diameters $\geq 26 \mu \mathrm{m}$. Control neurons of comparable size (contralateral and normal combined) had a significantly greater $(p<0.005)$ mean response of $9.1 \pm 1.1 \mathrm{pS} / \mu \mathrm{m}^{2}(n=15)$. Axotomized neurons with diameters $\leq 22 \mu \mathrm{m}$ had a mean response of $1.2 \pm 0.5 \mathrm{pS} /$ $\mu \mathrm{m}^{2}(n=6)$, while the corresponding control neurons of comparable size (contralateral and normal combined) had a significantly greater $(p<0.005)$ mean response of $14.1 \pm 3.3 \mathrm{pS} /$ $\mu \mathrm{m}^{2}(n=16)$. If cell size reflects cell type as it does in vivo, the data suggest that both choroid and ciliary neurons lose functional AChRs in response to axotomy.

GABA sensitivity. GABA at $50 \mu \mathrm{M}$ elicited responses from axotomized neurons that were not significantly different from those of unoperated contralateral neurons from the same chicks (Fig. 1). Responses of both populations, however, were lower than the responses of normal neurons from unoperated chicks (Fig. 1). The meaning of this difference is unclear. It is possible that the operation or exposure to anesthetic produced a systemic reduction in GABA responses that remained $5 \mathrm{~d}$ later. Concentrations of GABA ( 200 and $500 \mu \mathrm{M})$ adequate to produce nearmaximal responses failed to reveal differences between axotomized and normal neurons from unoperated chicks (12.8 \pm 1.4 $\mathrm{pS} / \mu \mathrm{m}^{2}, n=12$, vs. $11.1 \pm 1.5 \mathrm{pS} / \mu \mathrm{m}^{2}, n=13$, respectively). When either large cells alone or small cells alone were examined, their mean GABA response did not differ significantly from that obscrved for control cells (data not shown). The results indicate that axotomy does not unilaterally reduce the number of functional $\mathrm{GABA}_{\Lambda}$ receptors on the neurons, though there may be a bilateral reduction in GABA responses to low concentrations of agonist.

\section{Denervated neurons}

$A C h$ sensitivity. Denervation had little if any effect on the $\mathrm{ACh}$ response of ciliary ganglion neurons. Ten days after ganglia were denervated in newly hatched chicks, $30 \mu \mathrm{M}$ ACh induced a mean response from the neurons that was not significantly different either from that obtained from unoperated contralateral neurons of the same chicks or from normal neurons of unoperated chicks (Fig. 2). Similar results were obtained with high concentrations of $\mathrm{ACh}$. ACh at 0.5 and $1 \mathrm{~mm}$ induced equivalent responses from denervated neurons, and the combined values yield a mean of $11.4 \pm 3.3 \mathrm{pS} / \mu \mathrm{m}^{2}(n=14)$. This is not significantly different from the value of $13.4 \pm 1.7 \mathrm{pS} / \mu \mathrm{m}^{2}(n=20)$ obtained for control neurons at similar ACh concentrations. Changes in esterase levels can again be excluded from influencing the data, both because of the neostigmine tests described above and because carbachol $(200 \mu \mathrm{M})$ induced responses from denervated neurons $\left(3.5 \pm 2.7 \mathrm{pS} / \mu \mathrm{m}^{2}, n=5\right)$ that were not different from those of unoperated contralateral neurons $\left(2.9 \pm 1.5 \mathrm{pS} / \mu \mathrm{m}^{2}\right.$, $n=3$ ). Accordingly, the mean density of functional AChRs in the plasma membrane of denervated and normal neuron somas appears to be similar.

Averaging only the ACh responses of cells with diameters $\leq 22 \mu \mathrm{m}$ produces a value of $9.7 \pm 1.7 \mathrm{pS} / \mu \mathrm{m}^{2}(n=24)$ for denervated neurons, which is not significantly different from the value of $15.0 \pm 3.1 \mathrm{pS} / \mu \mathrm{m}^{2}(n=14)$ for control neurons. The 2 large denervated neurons ( $\geq 26 \mu \mathrm{m}$ diameters) present in the

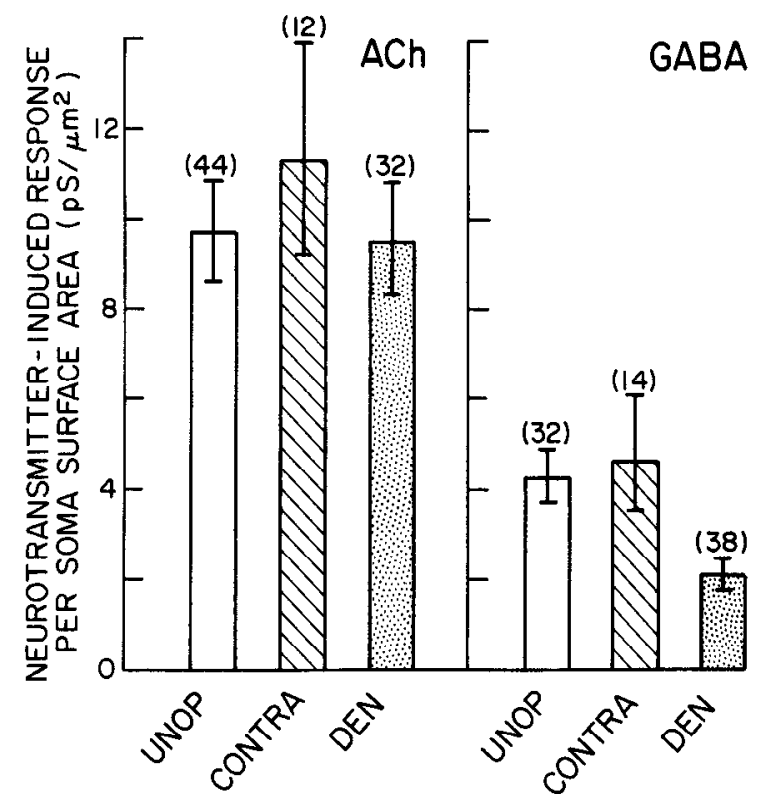

Figure 2. ACh and GABA responses of denervated neurons. Ciliary ganglia in newly hatched chicks were denervated by unilaterally transecting the oculomotor nerve, and $10 \mathrm{~d}$ later were removed and dissociated. Isolated neurons largely free of attached debris were tested for responses to $30 \mu \mathrm{M}$ ACh or $50 \mu \mathrm{M}$ GABA. Unop, normal neurons from unoperated chicks of the same age as operated chicks; contra, unoperated contralateral neurons from operated chicks; den, denervated neurons. Each determination represents the antilog geometric mean change in membrane conductance caused by the agonist per soma surface area, and the error bars represent the SEM as described in Materials and Methods. The numbers in parentheses indicate the number of neurons sampled. Data are from 5-7 separate experiments in which 5-8 ciliary ganglia were pooled per dissociation. The mean ACh response of denervated neurons was not significantly different from that of either set of control neurons. The mean GABA response of denervated neurons was significantly smaller than that of unoperated $(p<0.005)$ and contralateral $(p<0.025)$ neurons. Uncorrected whole-cell mean ACh responses were $12.2 \pm 1.8 \mathrm{nS}(n=34)$ for denervated neurons and 17.6 $\pm 1.7 \mathrm{nS}(n=56)$ for denervated-paired controls. Uncorrected wholecell mean GABA responses were $2.7 \pm 0.5 \mathrm{nS}(n=40)$ for denervated neurons and $8.1 \pm 1.2 \mathrm{nS}(n=46)$ for denervated-paired controls.

pool of tested cells had ACh responses of 13.6 and $20.4 \mathrm{pS} / \mu \mathrm{m}^{2}$, which fall in the upper range of those obtained for control neurons $\left(8.1 \pm 1.4 \mathrm{pS} / \mu \mathrm{m}^{2}, n=12\right)$ of the same size. Accordingly, neither large cells nor small cells appear to be preferentially affected by denervation.

GABA sensitivity. The response of denervated neurons to 50 $\mu \mathrm{M}$ GABA was reduced about 2-fold, compared with either unoperated contralateral neurons from the same chicks or normal neurons from unoperated chicks (Fig. 2). A reduction in the GABA response for denervated neurons was also observed when cells were tested with high concentrations of GABA to induce near-maximal responses. Pooling results obtained with GABA at $0.1-0.5 \mathrm{mM}$ yiclded mcan valucs of $5.1 \pm 1.1 \mathrm{pS} / \mu \mathrm{m}^{2}(n=$ 21) for denervated neurons and $12.4 \pm 1.6 \mathrm{pS} / \mu \mathrm{m}^{2}(n=25)$ for control neurons. The results indicate that the decline represents a reduced $G A B A$ response rather than a shift in the dose-response curve.

When the results were broken down according to cell size, a mean response of $2.3 \pm 2.6 \mathrm{pS} / \mu \mathrm{m}^{2}(n=4)$ was obtained to 50 $\mu \mathrm{M}$ GABA for denervated neurons $\geq 26 \mu \mathrm{m}$ in diameter, while a mean response of $1.8 \pm 0.4 \mathrm{pS} / \mu \mathrm{m}^{2}(n=25)$ was obtained 

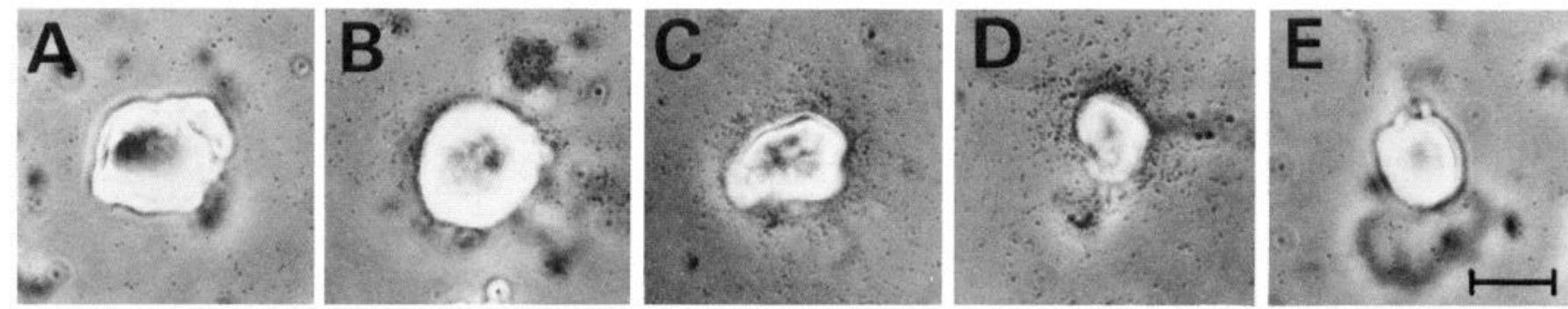

Figure 3. Autoradiographs of freshly dissociated neurons after surface labeling with a radiolabeled anti-AChR monoclonal antibody. Ciliary ganglia in 12-d-old chick (paired controls for denervated ganglia) were removed, dissociated, plated on polylysine-coated dishes, incubated with ${ }_{125} \mathrm{I}-\mathrm{mAb} 35$, rinsed, fixed, processed for autoradiography, and photographed with phase-contrast optics. Autoradiographic exposure time, 12 weeks; ${ }^{125} \mathrm{I}-\mathrm{mAb} 35$ specific activity, $0.5 \times 10^{18} \mathrm{cpm} / \mathrm{mol}$. $A$, An unlabeled neuron; $B$, a lightly labeled neuron; $C$, a moderately labeled neuron; $D$, a heavily labeled neuron; $E$, a nonspecifically labeled neuron (an excess of unlabeled $\mathrm{mAb} 35$ was included in the incubation with ${ }^{125} \mathrm{I}-\mathrm{mAb} 35$ ). Scale bar, $20 \mu \mathrm{m}$.

for those $\leq 22 \mu \mathrm{m}$ in diameter. These values are 43 and $51 \%$, respectively, of those obtained for control neurons of the corresponding cell diameter $\left(5.3 \pm 1.2 \mathrm{pS} / \mu \mathrm{m}^{2}, n=16\right.$, for large cells, and $3.4 \pm 0.7 \mathrm{pS} / \mu \mathrm{m}^{2}, n=11$, for small cells). For small cells, the response was significantly less than controls $(p<0.05)$; for large cells, the variation was too great for the pool size to permit a conclusion.

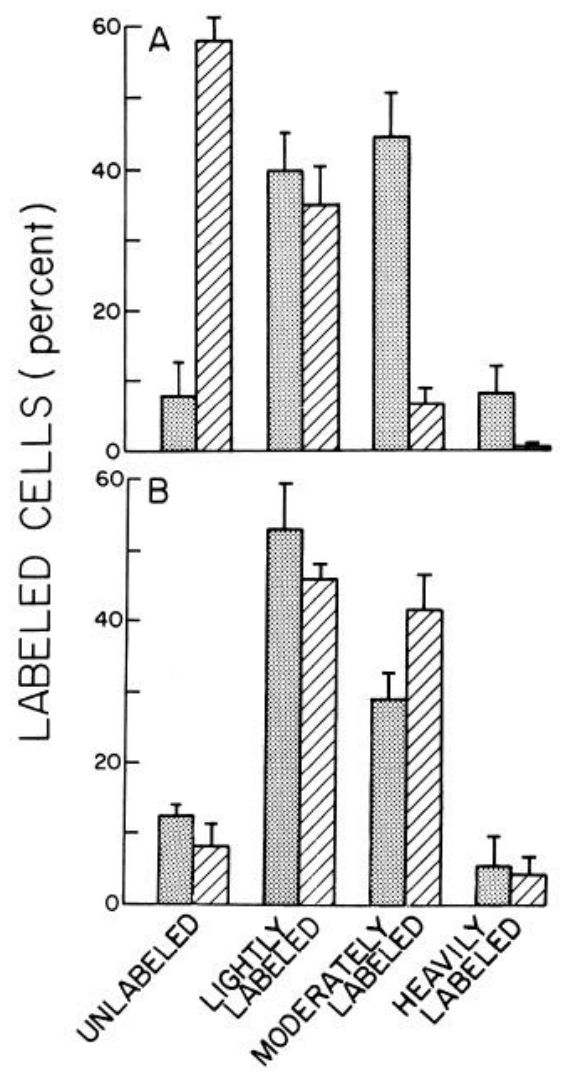

Figure 4. Distribution of ciliary ganglion neurons among the categories of labeling after binding radioiodinated anti-AChR monoclonal antibody. Operated (hatched bars) and unoperated contralateral (stippled bars) neurons from the same chicks were processed as described in Figure 3 and assigned to individual labeling categories. The results were tabulated and expressed as a percent of the total neurons scored. $A$, Axotomized $(n=304)$ and unoperated contralateral $(n=329)$ neurons ( 4 dishes per condition from 2 experiments). $B$, Denervated $(n=121)$ and unoperated contralateral $(n=356)$ neurons ( 4 and 2 dishes, respectively, per condition from 2 experiments).

\section{Autoradiography of surface AChRs}

Since not all AChRs on the surface of ciliary ganglion neurons are in a functionally available state (Margiotta et al., 1987a, b), it was important also to evaluate the effects of the operations on the total number of AChRs present on the soma surface. This was carried out using radioiodinated anti-AChR monoclonal antibody ${ }^{125} \mathrm{I}-\mathrm{mAb} 35$ and autoradiography. Freshly dissociated neurons were allowed to settle on a polylysine-coated culture dish and were then incubated with the antibody, rinsed, fixed, and processed for autoradiography. A range of labeling was observed even for unoperated neurons, and often a nonuniform distribution of grains was associated with the neuronal perimeter. To provide a semiquantitative comparison for the degree of antibody labeling among cells, neurons were assigned to 1 of 4 categories on the basis of relative grain density. Neurons with no detectable labeling were scored in category 1 ; lightly labeled, category 2 ; moderately labeled, category 3 ; and heavily labeled, category 4 (Fig. 3).

Autoradiographic analysis indicated that axotomized neurons had substantially fewer surface AChRs than did unoperated contralateral neurons from the same chicks. Though axotomized neurons included cells that fit each of the 4 labeling categories, a greater proportion of them fell in the lower labeling categories than did contralateral neurons (Fig. 4A). To evaluate the significance of the labeling shift, an index of grain density was constructed by multiplying the proportion of neurons in each category by the numerical value assigned to the category ( 1 to 4 ) and then summing the 4 determinations. The index of labeling calculated in this manner for axotomized neurons was $1.50 \pm$ 0.02 (4 dishes, 2 experiments). This was significantly different from unoperated contralateral neurons $(p<0.005)$, which had an index of $2.53 \pm 0.16$ ( 4 dishes, 2 experiments).

Most of the labeling was specific in that it could be prevented by including an excess of unlabeled mAb 35 in the original binding reaction with the ${ }^{125} \mathrm{I}-\mathrm{mAb} 35$. A small number of nonspecifically labeled neurons, however, fell in the lightly labeled category. Accordingly, indices of labeling were constructed for nonspecifically labeled cultures and found to be $1.23 \pm 0.05$ for axotomized neurons and $1.16 \pm 0.02$ for unoperated contralateral neurons. Subtracting these values from the total labeling indices produced means of $0.26 \pm 0.05$ and $1.37 \pm 0.16$ for axotomized and contralateral neurons, respectively.

In contrast to the results with axotomy, denervation had little effect on the number of surface AChRs. Denervated neurons not only contained examples of all 4 labeling categories, but the 
distribution of cells within the categories was indistinguishable from that of unoperated contralateral neurons from the same chicks (Fig. 4B). The labeling index of $2.42 \pm 0.03$ calculated for denervated neurons (4 dishes, 2 experiments) was not significantly different from the index of $2.27 \pm 0.13$ calculated for paired contralateral neurons ( 2 dishes, 1 experiment), or from the index for axotomized-paired contralateral neurons shown above.

\section{Discussion}

The results show that postganglionic axotomy dramatically decreases both the $\mathrm{ACh}$ response and the number of $\mathrm{AChRs}$ on the surface of chick ciliary ganglion neurons, while preganglionic denervation has little or no effect on either. Since both types of operations reduce the total number of ganglionic AChRs (Jacob and Berg, 1987), the present results demonstrate that the neurons can independently regulate surface and internal pools of AChRs. The results also suggest that different regulatory signals arise from the preganglionic input and the synaptic target tissue of the neurons. In contrast to the results with $\mathrm{AChRs,} \mathrm{axotomy}$ has no unilateral effect on the GABA response, while denervation decreases the response. The results indicate that cell-cell interactions differentially regulate the number of $A C h R s$ and $\mathrm{GABA}_{\mathrm{A}}$ receptors on ciliary ganglion neurons in vivo.

Measurements were made on freshly dissociated neurons rather than neurons in intact ganglia to assure access of agonist to the entire soma membrane. Neurons surviving the dissociation procedure appeared healthy by morphological and electrical criteria and had agonist sensitivities in the ranges expected from cell culture and whole ganglia experiments. The fact that axotomized and unoperated contralatcral neurons had equivalent GABA responses suggests that the decreased $\mathrm{ACh}$ responses did not represent cell damage following axotomy. Similarly, the normal ACh responses of denervated neurons provides reassurance about the specificity of the diminished GABA responses caused by denervation. The low cell yields, however, raise the concern that the tested neurons were not representative of all neurons in the ganglion. The tested populations did include both large and small cells characteristic of ciliary and choroid neurons, respectively. Nonetheless, selection may have occurred on some other basis. If selection did occur, it likely was equivalent for control and operated neurons since they were recovered in comparable numbers and had similar size distributions.

The decline in ACh sensitivity caused by postganglionic axotomy represents a decline in the average surface density of functional AChRs in the soma plasma membrane. This follows from the observation that the ACh response per unit surface area on the cell body is reduced in axotomized neurons, and the reduction cannot be accounted for by a change in the doseresponse curve for ACh or a change in cholinesterase activity on the cells. Since the entire cell body is bathed in ACh during the test, the response measured is likely to represent the summed contribution of most functional AChRs on the soma. Brenner and Martin (1976) previously obtained evidence that axotomy reduces the ACh sensitivity of the ciliary neuron subpopulation. They cut the ciliary nerves of ganglia in newly hatched chicks and used an iontophoretic method to measure ACh sensitivity at discrete loci on cells having the size and morphology of ciliary neurons. If cell size in preparations of freshly dissociated neurons is an indicator of cell type, i.e., ciliary vs. choroid, the present results suggest that axotomy reduces the ACh response of both classes of neurons.
Functional AChRs on chick ciliary ganglion neurons in culture have been estimated to comprise no more than $10 \%$ of the total number of AChRs in the plasma membrane, and the proportion of surface AChRs that are functionally available can be altered by culture conditions (Margiotta et al., 1987a, b). The present autoradiographic studies with ${ }^{125} \mathrm{I}$-mAb 35 indicate that the total number of AChRs detected by the antibody on the neuron surface is also decreased by axotomy. The results corroborate previous histochemical studies at the ultrastructural level, suggesting a decrease in synaptic AChRs after axotomy (Jacob and Berg, 1988).

Axotomy produced no unilateral change in the GABA response of the neurons, confirming that the decrease in ACh response was not representative of a global change in which all membrane receptors were reduccd. Whilc the GABA responses of axotomized neurons were equivalent to those of unoperated contralateral neurons, both were significantly smaller than responses of normal neurons from unoperated chicks. It is possible that the operation or the anesthetic produced a systemic effect in which GABA responses both from ipsilateral and contralateral neurons were affected as much as $5 \mathrm{~d}$ later (axotomy) but not $10 \mathrm{~d}$ later (denervation). The difference was observed at low but not high GABA concentrations, suggesting an effect on agonist affinity rather than receptor number. In any case, it is clear that axotomy produces a much larger reduction in the $\mathrm{ACh}$ response than in the GABA response of the neurons even if the comparison is not confined to unilateral effects.

The finding that preganglionic denervation has little or no effect either on the ACh response measured electrophysiologically or on the number of AChRs detected with ${ }^{125} \mathrm{I}-\mathrm{mAb} 35$ binding on the cell surface corroborates previous histochemical studies at the ultrastructural level showing no change in the number of synaptic AChRs after denervation (Jacob and Berg, 1988). The results are consistent with those of Dunn and Marshall (1985), who report no change in the distribution, magnitude, or time course of ACh responses from frog sympathetic neurons after denervation. Increased ACh responses have been reported for frog and mudpuppy cardiac ganglion neurons after denervation (Kuffler et al., 1971; Roper, 1976; Dennis and Sargent, 1979), but immunohistochemical studies indicate small changes in AChR distribution rather than an increase in the number of AChRs under these conditions (Sargent and Pang, 1988). It is unclear whether the immunohistochemical changes can account for the increased ACh responses observed for denervated cardiac ganglia.

Denervation of ciliary ganglia in the present experiments was confirmed by demonstrating the lack of accommodation responses and lack of contact from the preganglionic nerve both at the time of operation and at the time of ganglion dissection. Ultrastructural studies indicate that the majority of denervated neurons appear to have no preganglionic terminals on their soma surfaces (Jacob and Berg, 1988). It is possible that a few intraganglionic synapses formed between ciliary ganglion neurons in the $10 \mathrm{~d}$ period following the operation. Intraganglionic synapses do form between frog cardiac ganglion neurons (Sargent and Dennis, 1981) and between rabbit ciliary ganglion neurons (Johnson, 1988) in vivo after preganglionic denervation. The effect of intraganglionic synapses on $\mathrm{AChR}$ regulation is unknown.

Preganglionic denervation caused a significant unilateral reduction in the GABA response of ciliary ganglion neurons. The reduction appears to depend on a decline in the number of 
functional $\mathrm{GABA}_{\mathrm{A}}$ receptors on the cells since it cannot be accounted for by a shift in the dose-response curve. These results differ from a report of supersensitivity to GABA in the substantia nigra after denervation (Waszczak et al., 1981). A possible explanation involves the fact that chronic exposure to physiological concentrations of GABA down-regulates $\mathrm{GABA}_{\mathrm{A}}$ receptors both on CNS neurons and ciliary ganglion neurons in culture (McEachern et al., 1985; Maloteaux et al., 1987; Tehrani and Barnes, 1988). Denervation of the substantia nigra removes a known GABAergic input which may then release $\mathrm{GABA}_{\mathrm{A}}$ receptors from down-regulation. There is no evidence suggesting that preganglionic terminals in the ciliary ganglion contain GABA, so one would not anticipate the same effect in this case. Preganglionic denervation had no apparent effect on extracellularly recorded GABA-induced depolarizations in the postganglionic rami of sympathetic ganglia (Dunn and Marshall, 1985), but the conditions used might not have detected changes of the magnitude reported here.

Both preganglionic denervation and postganglionic axotomy substantially decrease the total number of AChRs in chick ciliary ganglia (Jacob and Berg, 1987). The present results, together with past studies (Jacob and Berg, 1988), demonstrate that denervation accomplishes this reduction by acting primarily on the large pool of intracellular AChRs in the neurons. Axotomy, in contrast, reduces the number of both surface and intracellular AChRs. Interestingly, axotomy and denervation each substantially reduce the amount of AChR mRNA encoding the $\alpha 3$ receptor subunit in the ganglion (Boyd et al., 1988). The fact that surface receptors are rapidly lost after axotomy but not after denervation implies that $\alpha 3 \mathrm{mRNA}$ is not rate-limiting for accumulation of $\mathrm{AChRs}$ on the soma surface.

The cell-cell interactions responsible for orchestrating AChR regulation in the neurons have yet to be identified. Clearly, denervation has a very different effect on chick ciliary ganglion AChRs than it does on vertebrate muscle AChRs. In the case of muscle, denervation substantially increases the amount of receptor (for reviews, see Fambrough, 1979, and Schuetze and Role, 1987) and the levels of AChR subunit mRNAs in the tissue (Goldman et al., 1988). The increases arise at least in part from the loss of muscle activity normally driven by the motor nerve. Different mechanisms may mediate the regulation of neuronal $\mathrm{AChRs}$ by innervation, and the mechanisms may vary among neuronal cell types.

Both the rapid decline in total ganglionic AChRs and the specific reduction of surface AChRs following axotomy in the present experiments differ from the results produced by surgical denervation of the neurons. It is likely that the effects of axotomy on ciliary ganglion AChRs are caused by the loss of the target tissue in the eye that normally provides a component acting on the neurons to maintain AChRs. The fact that many ciliary ganglion neurons have been observed to lose ACh sensitivity over the course of 2 weeks in culture (Crean et al., 1982), may reflect deprivation of such a component. It has been shown that the target tissue contains factors that enhance the survival, growth, and development of ciliary ganglion neurons in cell culture (Adler et al., 1979; Nishi and Berg, 1981; Barbin et al., 1984). Muscle cells, the normal synaptic targets of the ciliary ganglion, have been shown to promote retention of ACh sensitivity by the neurons in cell culture (Tuttle, 1983). Regulation of ciliary ganglion AChRs by information from the target tissue would provide a means by which the end organ could support and stabilize its own functional innervation.
Note added in proof: It has been reported that $\mathrm{AChRs}$ of bovine adrenal chromaffin cells in culture can be enhanced in function by a cAMP-dependent process and that AChRs newly inserted into the plasma membrane display greater efficacy than do older AChRs (Higgins and Berg, 1988a,b). We have found systematic errors in the assays used to measure receptor function in those studies. When the bovine adrenal chromaffin experiments are repeated with corrected assays, no effect of cAMP analogs is observed specifically on AChR function and no differences are found in the efficacy of "new" and "old" AChRs (A. McEachern and D. Berg, unpublished observations). Rather, cAMP analogs augment catecholamine release from the cells as reported, but do so in a manner independent of $\mathrm{AChR}$ function. In contrast, cAMP analogs do increase the ACh response of chick ciliary ganglion neurons as previously reported (Margiotta et al., 1987a; McEachern and Berg, unpublished observations). A more complete account will follow.

\section{References}

Adler, R., K. B. Landa, M. Manthorpe, and S. Varon (1979) Cholinergic neuronotrophic factors: Intraocular distribution of trophic activity for ciliary neurons. Science 204: 1434-1436.

Barbin, G., M. Manthorpe, and S. Varon (1984) Purification of the chick eye ciliary neuronotrophic factor. J. Neurochem. 43: 14681478.

Black, I. B., D. M. Chikaraishi, and E. J. Lewis (1985) Trans-synaptic increase in RNA coding for tryosine hydroxylase in a rat sympathetic ganglion. Brain Res. 339: 151-153.

Boyd, R. T., M. H. Jacob, S. Couturier, M. Ballivet, and D. K. Berg (1988) Expression and regulation of neuronal acetylcholine receptor mRNA in chick ciliary ganglia. Neuron 1: 495-502.

Brenner, H. R., and E. W. Johnson (1976) Physiological and morphological effects of post-ganglionic axotomy on presynaptic nerve terminals. J. Physiol. (Lond.) 260: 143-158.

Brenner, H. R., and A. R. Martin (1976) Reduction in acetylcholine sensitivity of axotomized ciliary ganglion cells. J. Physiol. (Lond.) 260: 159-175.

Choi, D. W., and G. D. Fischbach (1981) GABA conductance of chick spinal cord and dorsal root ganglion neurons in cell culture. J. Neurophysiol. 45: 605-620.

Corda, M. G., A. Concas, M. L. Porceddu, E. Sanna, and G. Biggio (1986) Striato-nigral denervation increases type II benzodiazepine receptors in the substantia nigra of the rat. Neuropharmacology 25: 59-62.

Crean, G., G. Pilar, J. B. Tuttle, and K. Vaca (1982) Enhanced chemosensitivity of chick parasympathetic neurones in co-culture with myotubes. J. Physiol. (Lond.) 331: 87-104.

Dennis, M. J., and P. B. Sargent (1979) Loss of extrasynaptic acetylcholine sensitivity upon reinnervation of parasympathetic ganglion cells. J. Physiol. (Lond.) 289: 263-275.

Dichter, M. A., and G. D. Fischbach (1977) The action potential of chick dorsal root ganglion neurones maintained in cell culture. J. Physiol. (Lond.)267: 281-298.

Dunn, P. M., and L. M. Marshall (1985) Lack of nicotinic supersensitivity in frog sympathetic neurones following denervation. J. Physiol. (Lond.) 363: 211-225.

Fambrough, D. M. (1979) Control of acetylcholine receptors in skeletal muscle. Physiol. Rev. 59: 165-227.

Giacobini, E., G. Pilar, J. Suszkiw, and H. Uchimura (1979) Normal distribution and denervation changes of neurotransmitter related enzymes in cholinergic neurones. J. Physiol. (Lond.) 286: 233-253.

Goldman, D., H. R. Brenner, and S. Heinemann (1988) Acetylcholine receptor $\alpha-, \beta-, \gamma$, and $\delta$-subunit mRNA levels are regulated by muscle aclivity. Neuron 1: 329-333.

Guidotti, A., K. Gale, A. Suria, and G. Toffano (1979) Biochemical evidence for two classes of GABA receptors in rat brain. Brain Res. 172: 566-571.

Halvorsen, S. W., and D. K. Berg (1987) Affinity labeling of neuronal acetylcholine receptor subunits with an $\alpha$-neurotoxin that blocks receptor function. J. Neurosci. 7: 2547-2555.

Hancock, A. A., E. N. Bush, D. Stanisic, J. J. Kyncl, and C. T. Lin 
(1988) Data normalization before statistical analysis: Keeping the horse before the cart. TIPS 9:29-33.

Higgins, L. S., and D. K. Berg (1988a) Metabolic stability and antigenic modulation of nicotinic acetylcholine receptors on bovine adrenal chromaffin cells. J. Cell Biol. 107: 1147-1156.

Higgins, L. S., and D. K. Berg (1988b) A cyclic AMP-dependent mechanism regulates acetylcholine receptor function on bovine adrenal chromaffin cells and discriminates between new and old receptors. J. Cell Biol. 107: 1157-1165.

Jacob, M. H., and D. K. Berg (1987) Effects of preganglionic denervation and postganglionic axotomy on acetylcholine receptors in the chick ciliary ganglion. J. Cell Biol. 105: 1847-1854.

Jacob, M. H., and D. K. Berg (1988) The distribution of acetylcholine receptors in chick ciliary ganglion neurons following disruption of ganglionic connections. J. Neurosci. 8: 3838-3849.

Jacob, M. H., J. M. Lindstrom, and D. K. Berg (1986) Surface and intracellular distribution of a putative neuronal acetylcholine receptor. J. Cell Biol. 103: 205-214.

Johnson, D. A. (1988) Regulation of intraganglionic synapses among rabbit parasympathetic neurones. J. Physiol. (Lond.) 397: 51-62.

Kuffler, S. W., M. J. Dennis, and A. J. Harris (1971) The development of chemosensitivity in extrasynaptic areas of the neuronal surface after denervation of parasympathetic ganglion cells in the heart of the frog. Proc. R. Soc. London [Biol.] 177: 555-563.

Maloteaux, J.-M., J.-N. Octave, A. Gossuin, C. Laterre, and A. Trouet (1987) GABA induces down-regulation of the benzodiazepine-GABA receptor complex in the rat cultured neurons. Eur. J. Pharmacol. 144: 173-183.

Margiotta, J. F., and D. K. Berg (1986) Enkephalin and substance P modulate synaptic properties of chick ciliary ganglion neurons in cell culture. Neuroscience 18: 175-182.

Margiotta, J. F., D. K. Berg, and V. E. Dionne (1987a) Cyclic AMP regulates the proportion of functional acetylcholine receptors on chicken ciliary ganglion neurons. Proc. Natl. Acad. Sci. USA 84: 81 55-8159.

Margiotta, J. F., D. K. Berg, and V. E. Dionne (1987b) The properties and regulation of functional acetylcholine receptors on chick ciliary ganglion neurons. J. Neurosci. 7: 3612-3622.

Marshall, L. M. (1985) Presynaptic control of synaptic channel kinetics in sympathetic neurones. Nature 317: 621-623.

McEachern, A. E., and D. K. Berg (1988) Benzodiazepine interactions

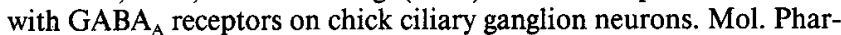
macol. 34: 129-135.

McEachern, A. E., J. F. Margiotta, and D. K. Berg (1985) $\gamma$-Aminobutyric acid receptors on chick ciliary ganglion neurons in vivo and in cell culture. J. Neurosci. 5: 2690-2695.

McEachern, A. E., M. H. Jacob, and D. K. Berg (1988) Effects of preganglionic denervation and postganglionic axotomy on $\mathrm{ACh}$ and GABA responses of chick ciliary ganglion neurons. Soc. Neurosci. Abstr. 14: 265.

Mueller, R. A., H. Thoenen, and J. Axelrod (1969) Increase in tyrosine hydroxylase activity after reserpine administration. J. Pharmacol. Exp. Ther. 169: 74-79.

Nishi, R., and D. K. Berg (1979) Survival and development of ciliary ganglion neurones grown alone in cell culture. Nature 277: 232-234.

Nishi, R., and D. K. Berg (1981) Two components from eye tissue that differentially stimulate the growth and development of ciliary ganglion neurons in cell culture. J. Neurosci. 1: 505-513.

$\mathrm{Nja}, \mathrm{A}$., and D. Purves (1978) The effects of nerve growth factor and its antiserum on synapses in the superior cervical ganglion of the guinea-pig. J. Physiol. (Lond.) 277: 53-75.

O'Lague, P. H., D. D. Potter, and E. J. Furshpan (1978) Studies on rat sympathetic neurons developing in cell culture. I. Growth characteristics and electrophysiological properties. Dev. Biol. 67: 384 403.

Pan, H. S., K. A. Frey, A. B. Young, and J. B. Penney, Jr. (1983) Changes in $\left[{ }^{3} \mathrm{H}\right] \mathrm{muscimol}$ binding in substantia nigra, entopeduncular nucleus, globus pallidus, and thalamus after striatal lesions as demonstrated by quantitative receptor autoradiography. J. Neurosci. 3: $1189-1198$

Pilar, G., and J. B. Tuttle (1982) A simple neuronal system with a range of uses: The avian ciliary ganglion. In Progress in Cholinergic Biology: Model Cholinergic Synapses, I. Hanin and A. M. Goldberg, eds., pp. 213-247, Raven, New York.

Ravdin, P. M., and D. K. Berg (1979) Inhibition of neuronal acetylcholine sensitivity by $\alpha$-toxins from Bungarus multicinctus venom. Proc. Natl. Acad. Sci. USA 76: 2072-2076.

Roper, S. (1976) The acetylcholine sensitivity of the surface membrane of multiply-innervated parasympathetic ganglion cells in the mudpuppy before and after partial denervation. J. Physiol. (Lond.) 254: $455-473$.

Sargent,.P. B., and M. J. Dennis (1981) The influence of normal innervation upon abnormal synaptic connections between frog parasympathetic neurons. Dev. Biol. 81: 65-73.

Sargent, P. B., and D. Z. Pang (1988) Denervation alters the size, number, and distribution of clusters of acetylcholine receptor-like molecules on frog cardiac ganglion neurons. Neuron 1: 877-886.

Schuetze, S. M., and L. W. Role (1987) Developmental regulation of the nicotinic acetylcholine receptor. Annu. Rev. Neurosci. 10: 403457.

Smith, M. A., J. F. Margiotta, and D. K. Berg (1983) Differential regulation of acetylcholine sensitivity and $\alpha$-bungarotoxin-binding sites on ciliary ganglion neurons in cell culture. J. Neurosci. 3: 23952402 .

Smith, M. A., J. Stollberg, J. M. Lindstrom, and D. K. Berg (1985) Characterization of a component in chick ciliary ganglia that crossreacts with monoclonal antibodies to muscle and electric organ acetylcholine receptor. J. Neurosci. 5: 2726-2731.

Smith, M. A., J. F. Margiotta, A. Franco, Jr., J. M. Lindstrom, and D. K. Berg (1986) Cholinergic modulation of an acetylcholine receptorlike antigen on the surface of chick ciliary ganglion neurons in cell culture. J. Neurosci. 6: 946-953.

Stollberg, J., and D. K. Berg (1987) Neuronal acetylcholine receptors: Fate of surface and internal pools in cell culture. J. Neurosci. 7: 18091815.

Tehrani, M. H. J., and E. M. Barnes, Jr. (1988) GABA down-regulates the GABA/benzodiazepine receptor complex in developing cerebral neurons. Neurosci. Lett. 87: 288-292.

Tuttle, J. B. (1983) Interactions with membrane remnants of target myotubes maintains transmitter sensitivity of cultured neurons. Science 220: 977-979.

Waddington, J. L., and A. J. Cross (1978) Denervation supersensitivity in the striatonigral GABA pathway. Nature 276: 618-620.

Waszczak, B. L., C. Hume, and J. R. Walters (1981) Supersensitivity of substantia nigra pars reticulata neurons to GABAergic drugs after striatal lesions. Life Sci. 28: 2411-2420. 